\title{
Analysis of Anthocyanins Extracted from the Acai Fruit (Euterpe oleracea): A Potential Novel Vital Dye for Chromovitrectomy
}

\author{
Cristiane S. Peris, ${ }^{1}$ Rafael R. Caiado, ${ }^{1}$ Acácio Alves Souza Lima-Filho, ${ }^{1,2}$ \\ Eduardo B. Rodrigues, ${ }^{1}$ Michel Eid Farah, ${ }^{1}$ Mariana Batista Gonçalves, \\ Bruno de Queiroz Alves, ${ }^{1}$ Joao Guilherme Palma Urushima, ${ }^{1}$ Raul Ragazzi, ${ }^{1,2}$ \\ and Mauricio Maia (iD) \\ ${ }^{1}$ Department of Ophthalmology, Federal University of São Paulo, Botucatu Street, 816-Vila Clementino, 04023-062 São Paulo, \\ SP, Brazil \\ ${ }^{2}$ Ophthalmos S/A, Brigadeiro Luís Antônio Avenue, 4830-Jardim Paulista, 01401-002 São Paulo, SP, Brazil \\ ${ }^{3}$ Brazilian Institute of Fight Against Blindness, Otto Ribeiro Avenue, 901-Jardim Paulista, 19814-470 Assis, SP, Brazil
}

Correspondence should be addressed to Mauricio Maia; maiamauricio@terra.com.br

Received 10 March 2018; Accepted 17 May 2018; Published 19 July 2018

Academic Editor: Anat Loewenstein

Copyright (C) 2018 Cristiane S. Peris et al. This is an open access article distributed under the Creative Commons Attribution License, which permits unrestricted use, distribution, and reproduction in any medium, provided the original work is properly cited.

\begin{abstract}
Purpose. To classify and quantify anthocyanins in a vital dye extracted from the acai fruit (Euterpe oleracea), adjust $\mathrm{pH}$ and osmolarity, and perform lyophilization to develop a new chromovitrectomy dye. Methods. Three dye concentrations 10\%, 25\%, and 35\% (equivalent to 100, 250, and $350 \mathrm{mg}$ of lyophilized acai fruit pulp extract samples) were evaluated when diluted in $1 \mathrm{ml}$ of phosphatebuffered solution ( $\mathrm{pH} 7$ and $300 \mathrm{mOsm}$ ). The dye was analyzed by mass spectrometry and high-performance liquid chromatography (HPLC) to identify and quantify anthocyanins molecules. Results. The $\mathrm{pH}$ and osmolarity correction and lyophilization were performed without damaging the anthocyanin molecular structure. Mass spectrometry confirmed the presence of five anthocyanins in the three concentrations of the dye. Cyanidin-3-O-glucoside was the major anthocyanin found. HPLC showed that the concentration of anthocyanin was similar, independent of the dye concentration tested. Conclusions. Lyophilization and the correction of $\mathrm{pH}$ and osmolarity (7.00 and $300 \mathrm{mOsm}$, resp.) were performed successfully. Five anthocyanins are present in the dye from the acai fruit. The major anthocyanin is cyanidin-3-O-glucoside. Independent of the dye concentration tested, the anthocyanin concentration was similar. Standardized chemical characteristics of this new dye may allow its use during chromovitrectomy in humans.
\end{abstract}

\section{Introduction}

The acai fruit (Euterpe oleracea) from the palm tree is native to the Amazon forest in Brazil. In addition to being one of the main trees that produce palm hearts, the acai palm also produces a fruit with high nutritional properties and economic value for the food and cosmetic industries. The acai fruit has been described as caloric and rich in proteins, polyunsaturated fatty acids, and sugars (Table 1) [1].

Carotenoids and anthocyanins are among the main components of the acai fruit [2-4]. Anthocyanins, derived from the Greek words anthos (flower) and kianos (blue), are part of a large group of organic components known as flavonoids that are represented by the basic chemical structure C6-C3-C6 (Figure 1). The phenolic structure of an anthocyanin provides an antioxidant effect due to electron donation or transference of hydrogen atoms.

It has been suggested that photosensitizing dyes used in chromovitrectomy could enhance phototoxicity by increasing levels of free radicals, creating a photoproduct that could be harmful to retinal cells. The antioxidant effects of anthocyanins theoretically could quench the singlet oxygen, which is released during chromovitrectomy [5-7]. The antioxidant property of the acai dye, associated with its high affinity for the internal limiting membrane (first observed in cadaveric eyes by our research team), became the basis for the development of a novel dye [8]. 
TABLE 1: Reference of nutritional values from 100 grams of acai fruit (E. oleracea) pulp on a diet of $2,500 \mathrm{kcal} /$ day.

\begin{tabular}{lc}
\hline Protein & $13 \mathrm{~g}$ \\
Iron & $26 \mathrm{~g}$ \\
Fibers & $34 \mathrm{~g}$ \\
Phosphorus & $227 \mathrm{~g}$ \\
Sodium & $56.4 \mathrm{~g}$ \\
Vitamin C & $17 \mathrm{mg}$ \\
Potassium & $932 \mathrm{mg}$ \\
Vitamin E & $45 \mathrm{mg}$ \\
Calcium & $286 \mathrm{mg}$ \\
Lipids & $17 \mathrm{mg}$ \\
Magnesium & $174 \mathrm{mg}$ \\
Glycides & $36 \mathrm{mg}$ \\
Calorie value & $349 \mathrm{kcal}$ \\
\hline
\end{tabular}

Source: Federal University of Para State, Brazil.<smiles></smiles>

FIgURE 1: Basic molecular structure of the anthocyanins.

In 2017, our research group found that the $10 \%$ and $25 \%$ concentrations of the acai dye were safe when used in a rabbit model [9]. In this study, rabbits were injected intravitreously with the acai dye in three concentrations: $10 \%, 25 \%$, and 35\%. Control eyes received balanced salt solution. Functional evaluations were performed using electroretinography while morphologic examinations were performed by fundus imaging, fluorescein angiography, optical coherence tomography, light microscopy, and transmission electron microscopy. The 10\% and 25\% dye concentrations from the acai fruit did not cause significant functional or morphological toxicity. However, the 35\% concentration showed evidence of morphologic and functional abnormalities suggestive of temporary toxic effects at $24 \mathrm{~h}$ follow-up.

Hence, the highest concentration of the acai fruit that was safe and effective in the rabbit model was $25 \%$. This concentration was used for the sequence of a phase I/II clinical trial in 25 humans (unpublished data).

The objectives of the current study were to classify and quantify the anthocyanins of the acai fruit dye in the concentrations of $10 \%, 25 \%$, and $35 \%$. This information will become the basis for further understanding the antioxidant behavior of the acai dye.

\section{Materials and Methods}

2.1. Sample Preparation. The commercial acai extract was divided into flasks of 100, 250, and $350 \mathrm{mg}$ of lyophilized
TABLE 2: Gradient used for liquid chromatography analysis of five major anthocyanins.

\begin{tabular}{lccc}
\hline Time & Phase A $(\%)$ & Phase B (\%) & Flow (mL/minute) \\
\hline 0.0 & 95 & 5 & 1.00 \\
5.0 & 95 & 5 & 1.00 \\
20.0 & 5 & 95 & 1.00 \\
25.0 & 95 & 5 & 1.00 \\
27.0 & 95 & 5 & 1.00 \\
35.0 & 95 & 5 & 1.00 \\
\hline
\end{tabular}

anthocyanin powder to produce the concentrations of $10 \%$, $25 \%$, and $35 \%$, respectively.

Ophthalmos SA (São Paulo, Brazil) developed the lyophilization process for the final dye preparation that was comprised mainly of anthocyanins. This process was performed in a sterile environment, stabilized at $-50^{\circ} \mathrm{C}$ for 24 hours, and diluted in $1 \mathrm{ml}$ of polyvinyl alcohol in the $10 \%$, $25 \%$, and $35 \%$ concentrations. The $\mathrm{pH}$ of the natural extract was acidic [10]. Hence, both the $\mathrm{pH}$ and osmolarity ( $\mathrm{pH} 7.00$; $300 \mathrm{mOsm}$ ) were controlled and established using one milliliter of phosphate-buffered solution (PBS). These concentrations also reflect the most suitable values obtained in preliminary studies in which factors such as staining capacity, $\mathrm{pH}$, osmolarity, solubility, and stability were considered.

The lyophilized dye solutions were stored in depyrogenized amber flasks based on our previous results that anthocyanin molecules are highly unstable and light exposure might modify the staining capacity of the dye [9]. The anthocyanins were then analytically characterized by mass spectrometry.

2.2. Mass Spectrometry. Twenty-five-milligram samples of the raw materials and final products were subjected to mass spectrometry to compare the specific molecules in lower to higher quantities. This analysis was based on a spectral data bank. SGB Chemical Consultant Ltda. (São Paulo, Brazil), which was blinded to the dye components, analyzed the three lyophilized samples.

\subsection{High-Performance Liquid Chromatography (HPLC).} Three microliters of dimethyl sulfoxide (DMSO) (Vetec Ventiltechnik $\mathrm{GmbH}$ ) and $7.0 \mathrm{~mL}$ of the solution from the mobile phase were added to the flasks with the dye concentrations. These were then put in an ultrasonic bath, and the extraction process continued for 10 minutes. The flasks were removed from the bath, and the solutions were filtered into $1.5 \mathrm{~mL}$ vials containing a filter 0.22 micrometer in diameter. Finally, $20 \mu \mathrm{L}$ was added to the HPLC stabilized system.

The analysis was performed using the 1260 Infinity II liquid chromatography system and a diode array detector (Agilent Technologies, Santa Clara, CA). The specific methodology used a $5 \mu \mathrm{m} 150 \times 4.6 \mathrm{~mm}$ Agilent Eclipse Column XDB C18 (Agilent Technologies). The mobile phase with an aqueous solution of $0.1 \%$ trifluoroacetic acid was referred to as phase A and acetonitrile HPLC was referred to as phase $\mathrm{B}$. 


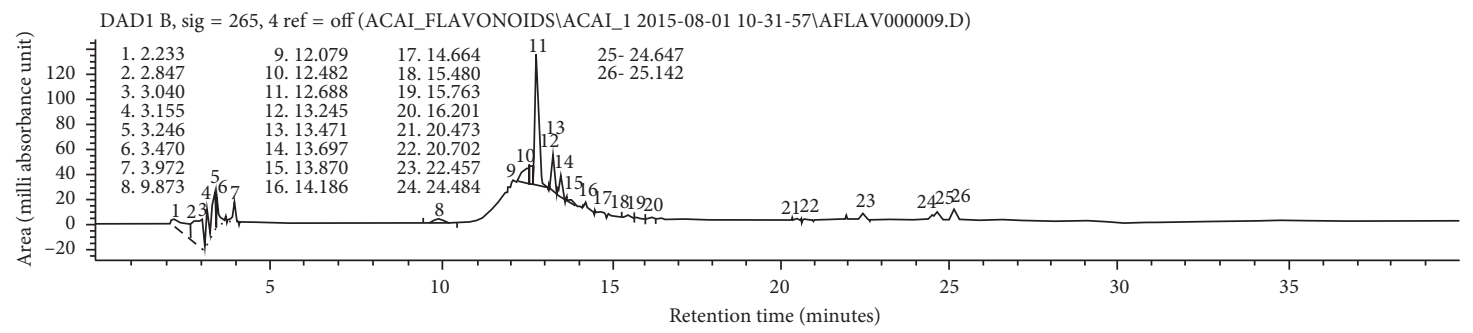

DAD1 B, sig = 350, 4 ref = off (ACAI_FLAVONOIDS \ACAI_1 2015-08-01 10-31-57\AFLAV000009.D)
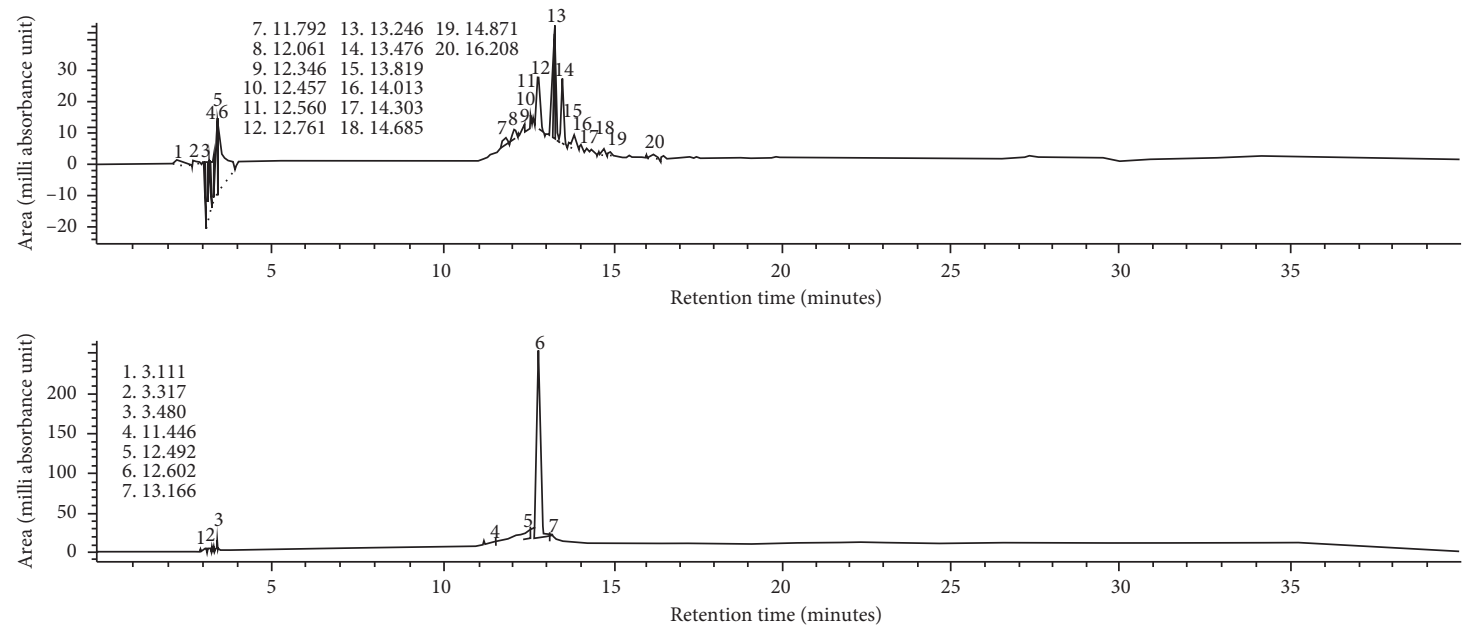

(a)

DAD1 A, sig $=265,4 \mathrm{ref}=\mathrm{off}$ (ACAI_FLAVONOIDS\ACAI_1 2015-08-01 10-31-57\AFLAV000011.D)
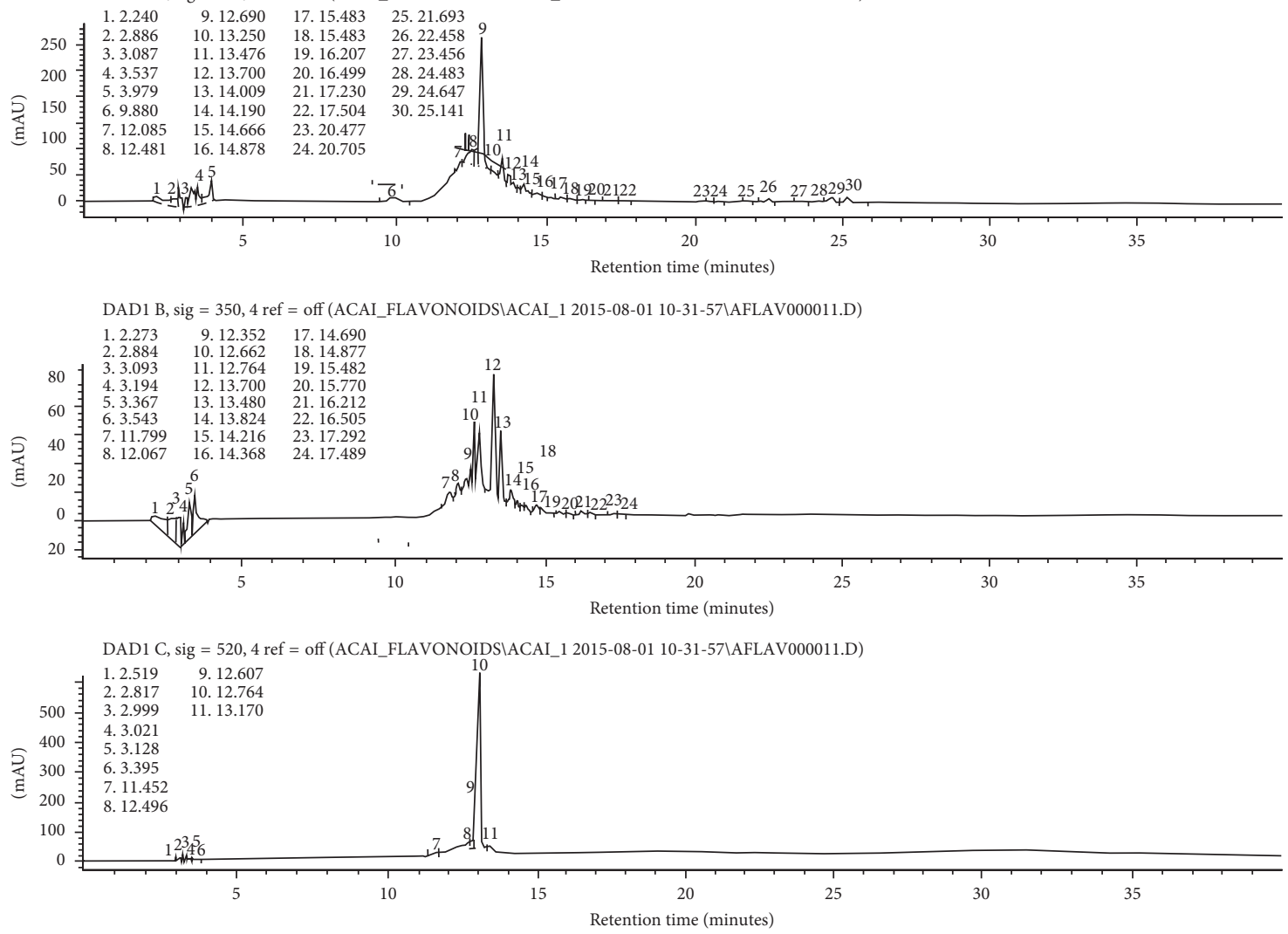

(b)

FIgURE 2: Continued. 

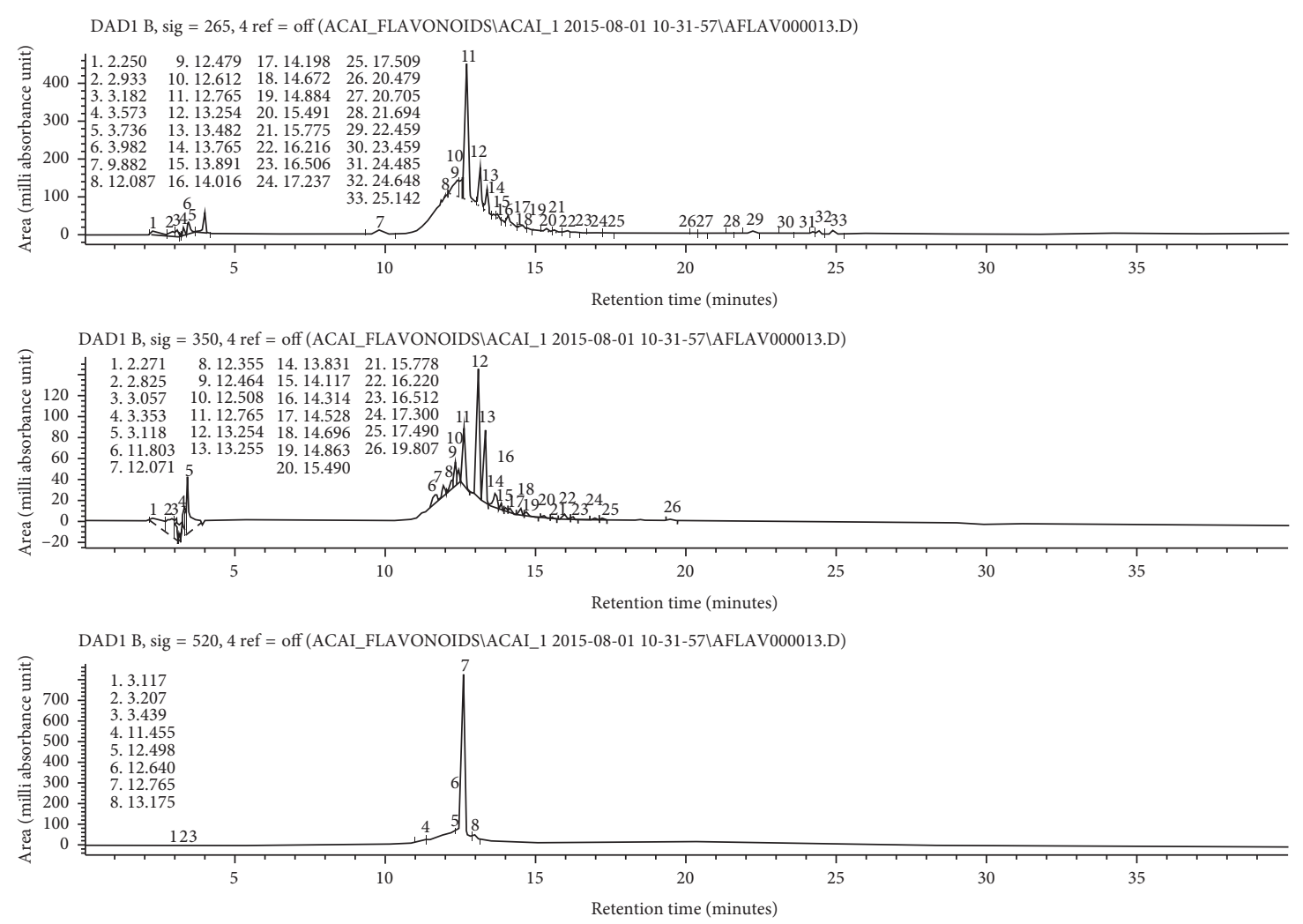

(c)

Figure 2: (a) A mass spectrometry graph of the $10 \%$ concentration of the vital dye extracted from the acai fruit. (b) A mass spectrometry graph of the $25 \%$ concentration of the vital dye extracted from the acai fruit. (c) A mass spectrometry graph of the $35 \%$ concentration of the vital dye extracted from the acai fruit.

The reagents used water (produced with purified water from a permutation technique), trifluoroacetic acid (Vetec Ventiltechnik GmbH, Speyer-am-Rhein, Germany), DMSO, and acetonitrile HPLC (Sigma-Aldrich, St. Louis, MO). This analysis used the gradients listed in Table 2, thus enabling quantification of all anthocyanins in the same chromatogram.

For the anthocyanin quantification using HPLC, it was first necessary to obtain the anthocyanin profiles using mass spectrometry. This information was used to determine the analytical standards of the anthocyanins which were then obtained from ChromaDex Inc. (Irvine, CA).

Five 25-milligram samples of the same major isolated anthocyanin molecules were used as comparative patterns from higher to lower quantities: cyanidin-3-O-glucoside, homoorientin, orientin, taxifolin, and isovitexin. The same amount $(2.0 \pm 0.20 \mathrm{mg})$ of the anthocyanin chemical standards was weighed in separate $10 \mathrm{~mL}$ volumetric flasks of $10 \mathrm{ml}$ each. Subsequently, $3 \mathrm{~mL}$ of DMSO was added to each flask and subjected to high-frequency ultrasound for 5 minutes until the mobile phase. The patterns were mixed and diluted with the mobile phase.

The anthocyanin concentrations were quantified by HPLC using an electrochemical detector. The 350-nanometer wavelength was identified by the detector showing $1.00 \mathrm{~mL} / \mathrm{min}$ flow by maintaining the column with the aid of a $40^{\circ} \mathrm{C}$ oven. The five molecules were used in the mobile phase of the solution in $10 \mathrm{ml} /$ vial containing water and
$30 \%$ DMSO without being retained in the filter. Such data were used to obtain the anthocyanin concentration for each concentration of the dye.

\section{Results}

3.1. $\mathrm{pH}$ and Osmolarity. Correction of $\mathrm{pH}$ and osmolarity and the lyophilization process were performed successfully.

3.2. Mass Spectrometry. This analysis showed the presence of five anthocyanins in the vital dye of the acai fruit from lower to higher quantities: taxifolin, orientin, isovitexin, homoorientin, and cyanidin-3-O-glucoside. Mass spectrometry analysis of the $10 \%, 25 \%$, and $35 \%$ concentrations of the vital dye are shown in Figure 2.

3.3. HPLC. This analysis quantified the five major anthocyanins in the vital dye of the acai fruit in the three tested concentrations based on the retention time by area shown in the chromatographs (Figures 3(a)-3(c)). Results showed that independent of the concentration of the acai dye, the anthocyanin concentration was similar (Table 3).

Chromatography results were compared with those of the isolated patterns, which facilitated confirmation of the presence of the anthocyanin molecules through separation of the flavonoids (Figures 4(a)-4(e)). 


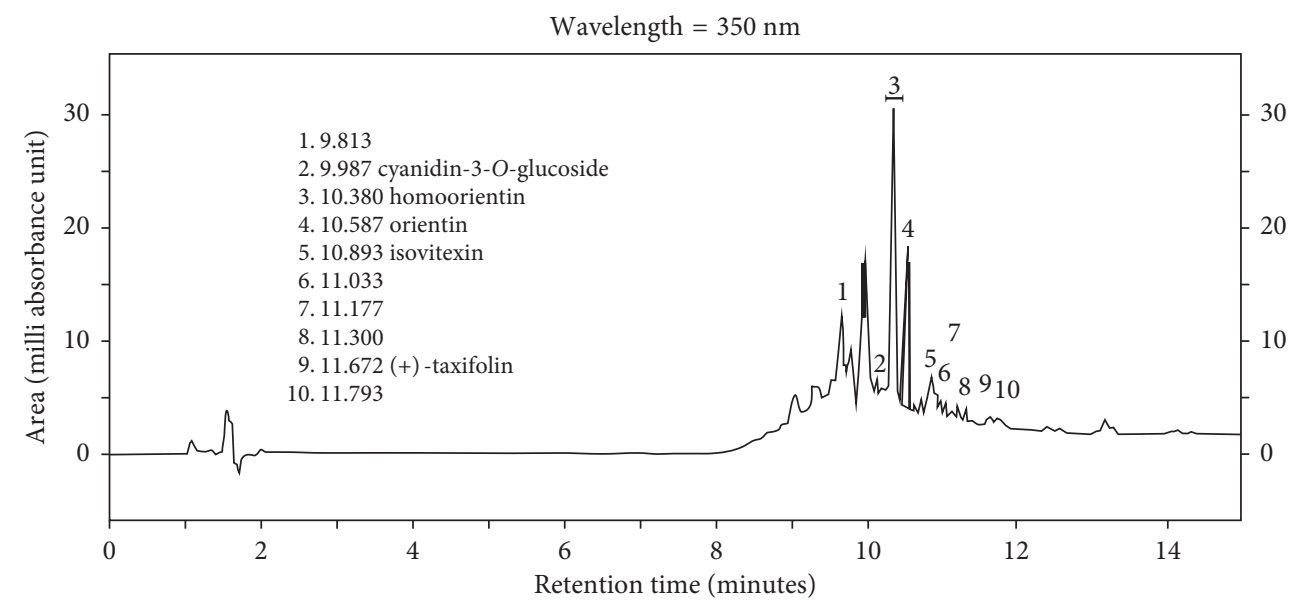

(a)

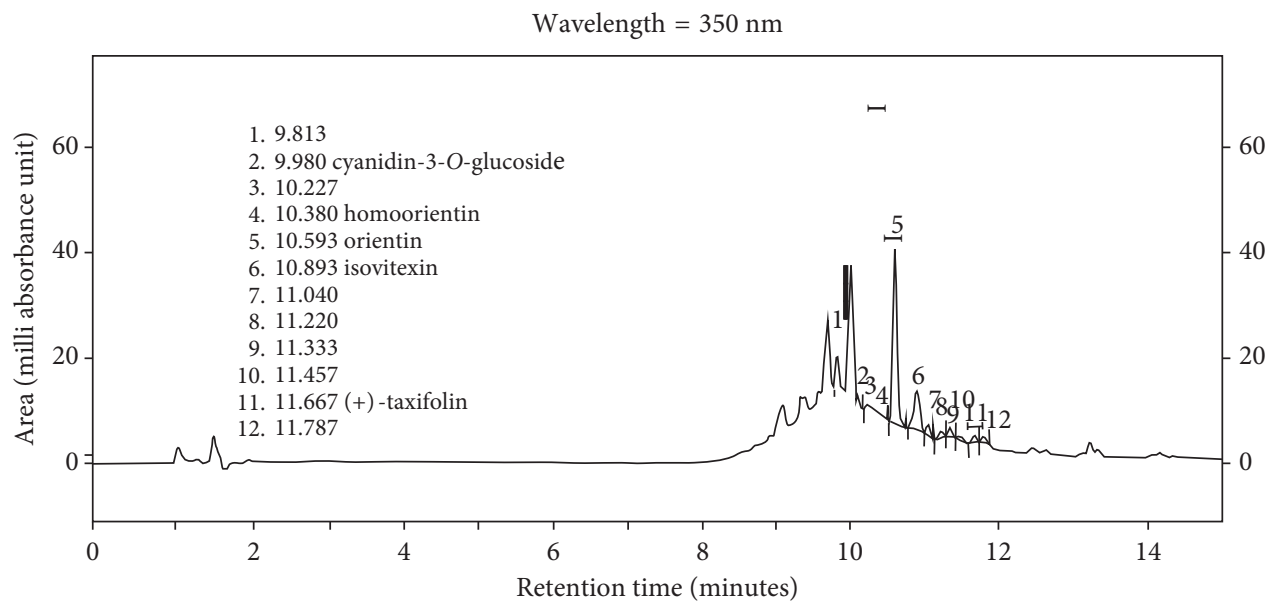

DAD: signal D, $350.0 \mathrm{~nm} / \mathrm{Bw}: 4.0 \mathrm{~nm}$ Sample 81-2

(b)

Wavelength $=350 \mathrm{~nm}$

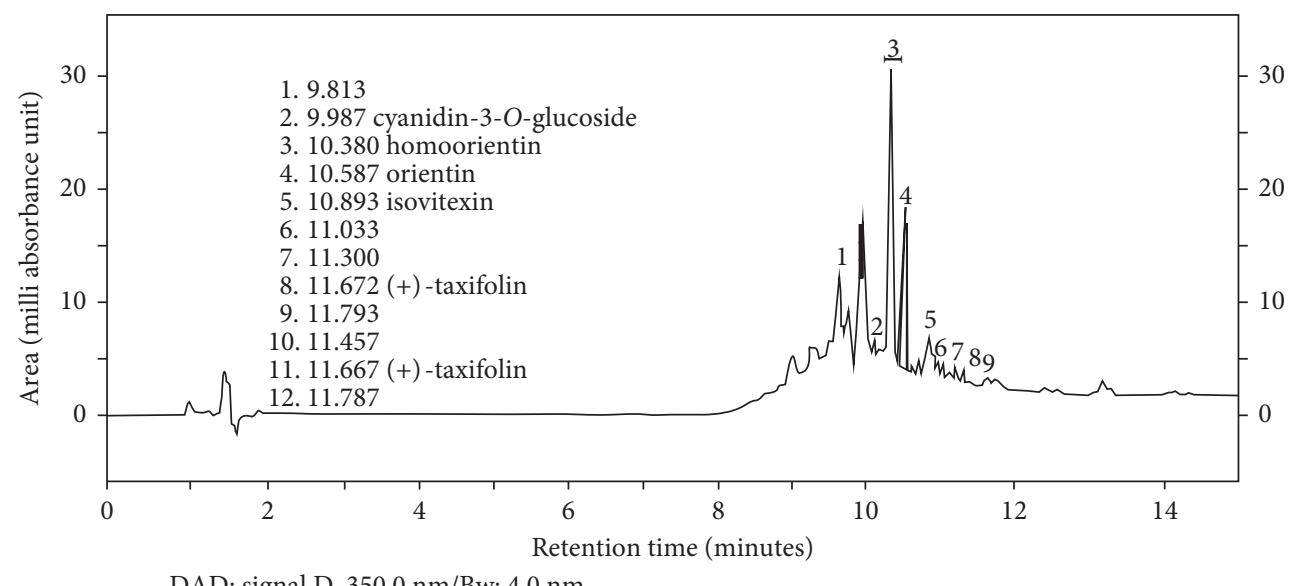

DAD: signal D, $350.0 \mathrm{~nm} / \mathrm{Bw}: 4.0 \mathrm{~nm}$

Sample 80-2

(c)

FIGURE 3: (a) A chromatograph of the 80-2 vital dye extracted from the acai fruit in a $10 \%$ concentration (equivalent to $100 \mathrm{mg}$ of a lyophilized sample extracted from the acai pulp diluted in $1 \mathrm{ml} \mathrm{PBS} \mathrm{(pH} \mathrm{7.00;} 300 \mathrm{mOsm}$ ). (b) A chromatograph of 81-2 vital dye extracted from the acai fruit in a $25 \%$ concentration (equivalent to $250 \mathrm{mg}$ of a lyophilized sample extracted from the acai pulp diluted in $1 \mathrm{ml} \mathrm{PBS} \mathrm{(pH}$ $7.00 ; 300 \mathrm{mOsm}$ ). (c) A chromatograph of $82-2$ vital dye extracted from the acai fruit in a $35 \%$ concentration (equivalent to $350 \mathrm{mg}$ of lyophilized extracted from the acai pulp diluted in $1 \mathrm{ml}$ PBS ( $\mathrm{pH} 7.00 ; 300 \mathrm{mOsm})$ ). 
TABLE 3: Quantification of the anthocyanins based on the retention time by area of HPLC results at the three concentrations.

\begin{tabular}{|c|c|c|c|}
\hline Anthocyanins & $10 \%$ concentration & $25 \%$ concentration & $35 \%$ concentration \\
\hline $\begin{array}{l}\text { Cyanidin-3-O-glucoside } \\
\text { Retention time (minutes) } \\
\text { Area (milli absorbance unit) }\end{array}$ & $\begin{array}{c}9.987 \\
23.909\end{array}$ & $\begin{array}{c}9.980 \\
24.410\end{array}$ & $\begin{array}{c}9.973 \\
23.886\end{array}$ \\
\hline $\begin{array}{l}\text { Homoorientin } \\
\text { Retention time (minutes) } \\
\text { Area (milli absorbance unit) }\end{array}$ & $\begin{array}{l}10.380 \\
38.511 \\
\end{array}$ & $\begin{array}{l}10.380 \\
36.950 \\
\end{array}$ & $\begin{array}{l}10.380 \\
40.106 \\
\end{array}$ \\
\hline $\begin{array}{l}\text { Orientin } \\
\text { Retention time (minutes) } \\
\text { Area (milli absorbance unit) }\end{array}$ & $\begin{array}{l}10.587 \\
22.945 \\
\end{array}$ & $\begin{array}{l}10.593 \\
22.784 \\
\end{array}$ & $\begin{array}{l}10.580 \\
23.988 \\
\end{array}$ \\
\hline $\begin{array}{l}\text { Taxifolin } \\
\text { Retention time (minutes) } \\
\text { Area (milli absorbance unit) }\end{array}$ & $\begin{array}{c}11.673 \\
0.966 \\
\end{array}$ & $\begin{array}{c}11.667 \\
0.894 \\
\end{array}$ & $\begin{array}{c}11.667 \\
0.998 \\
\end{array}$ \\
\hline $\begin{array}{l}\text { Isovitexin } \\
\text { Retention time } \\
\text { Area (milli absorbance unit) }\end{array}$ & $\begin{array}{c}10.893 \\
6.755\end{array}$ & $\begin{array}{c}10.893 \\
6.737\end{array}$ & $\begin{array}{c}10.880 \\
6.194\end{array}$ \\
\hline
\end{tabular}

HPLC chromatogram of cyanidin-3-O-glucoside (CDXA-13-3273)

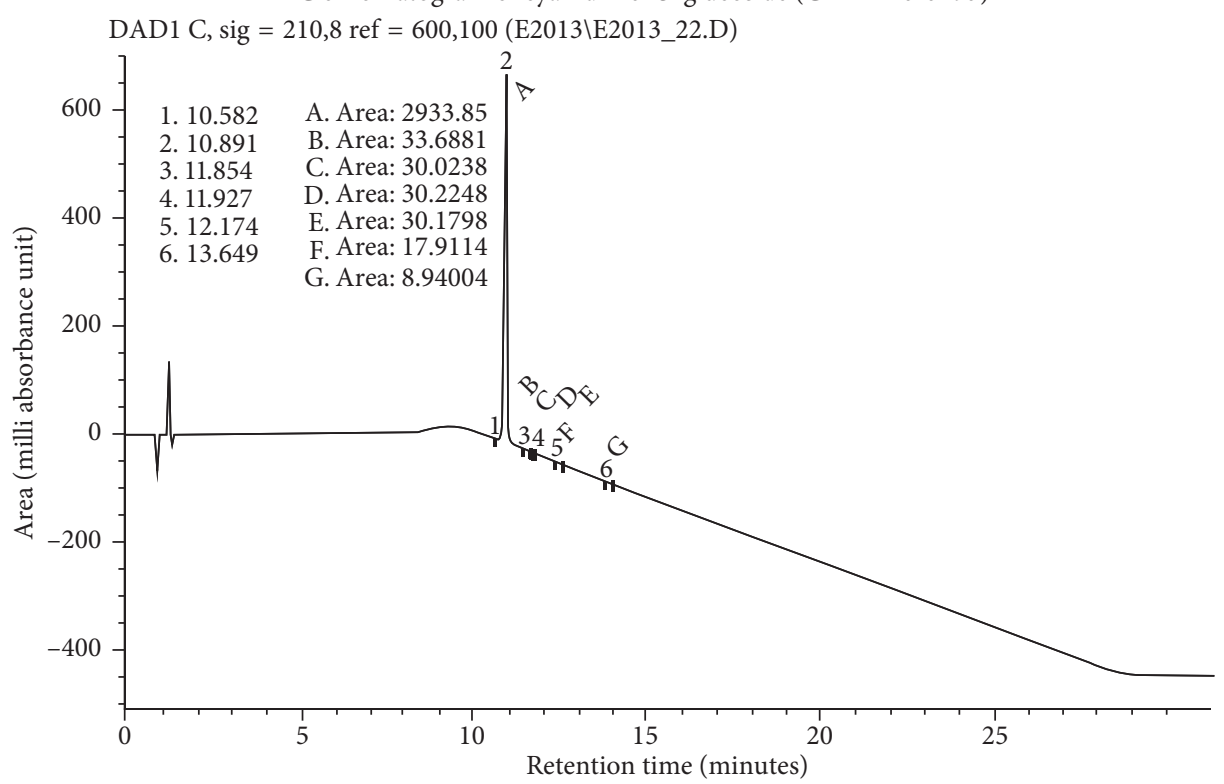

(a)

HPLC Chromatogram of $(+)$-taxifolin (CDXA-13-5818)

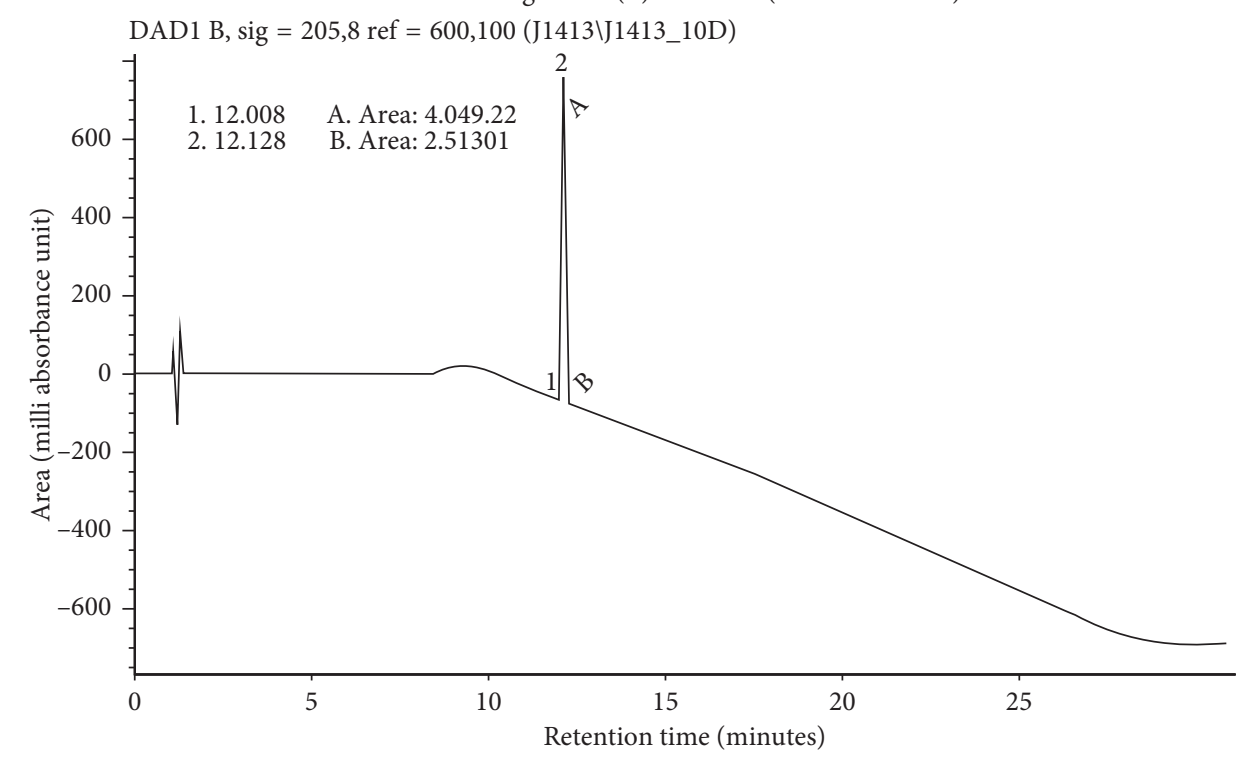

(b)

Figure 4: Continued. 
HPLC chromatogram of orientin (CDXA-12-7714)

DAD1 A, sig = 250,80 ref = 600,100 (X:|YOUNG|DATA 2012\K0712\K0712_04.D)

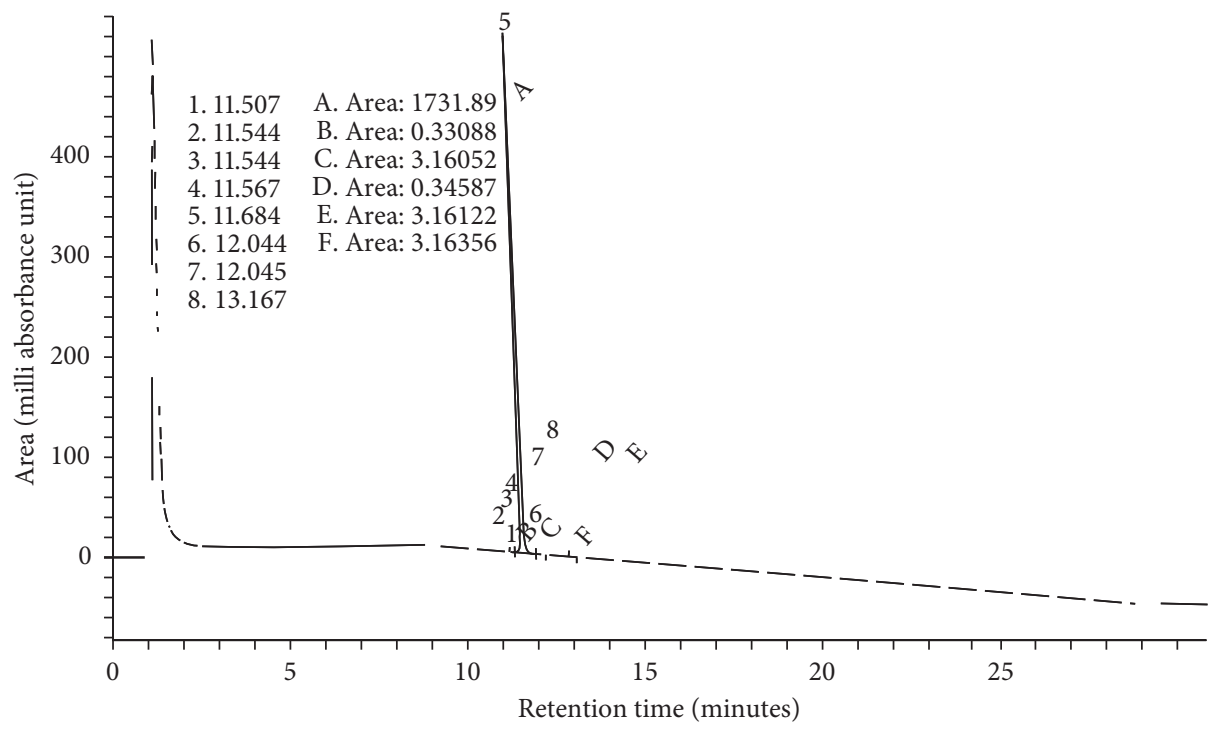

(c)

HPLC chromatogram of isovitexin (CDXA-13-4304)

DAD1 C, sig $=210,8$ ref $=600,100($ GO113\GO113_05.D)

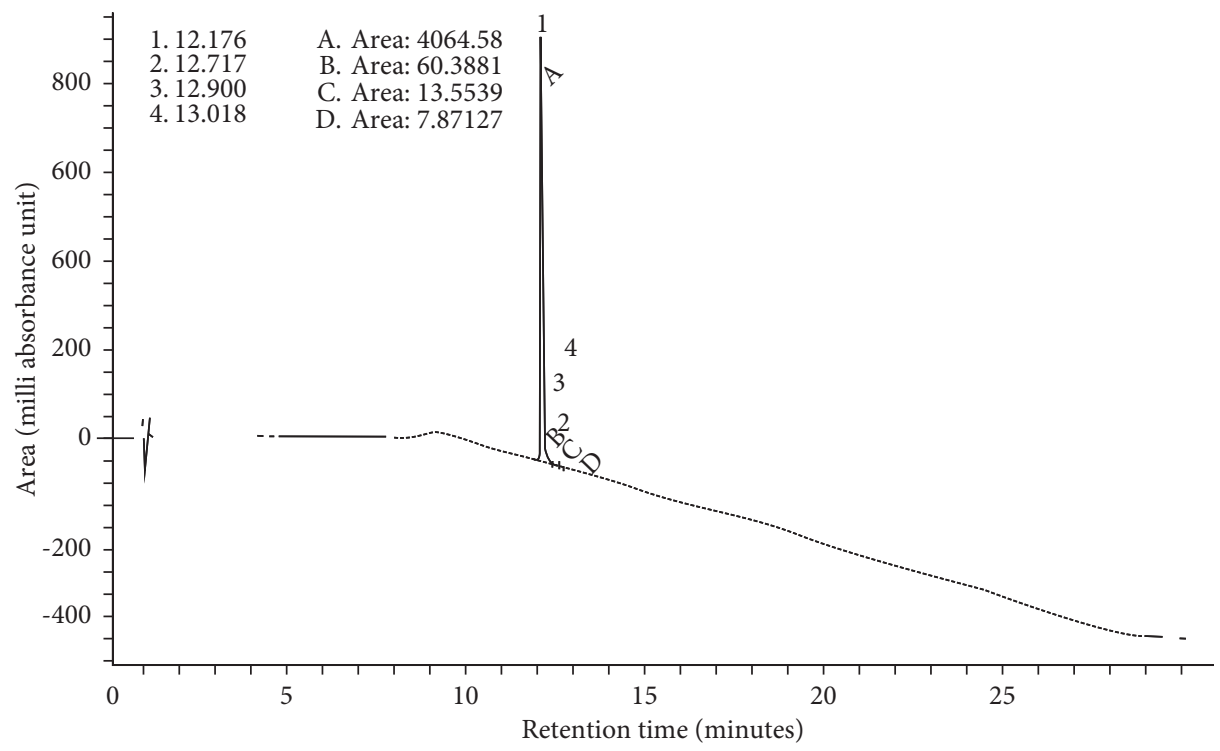

(d)

FIgUre 4: Continued. 
HPLC chromatogram of homoorientin (CDXA-11-4337)

- DAD1 A, sig = 250,80 ref = 600,100 (C:\HPCHEM \ZEEMAN\DATA $\left.2011 \backslash H 2511 \backslash H 2511 \_05 . D\right)$

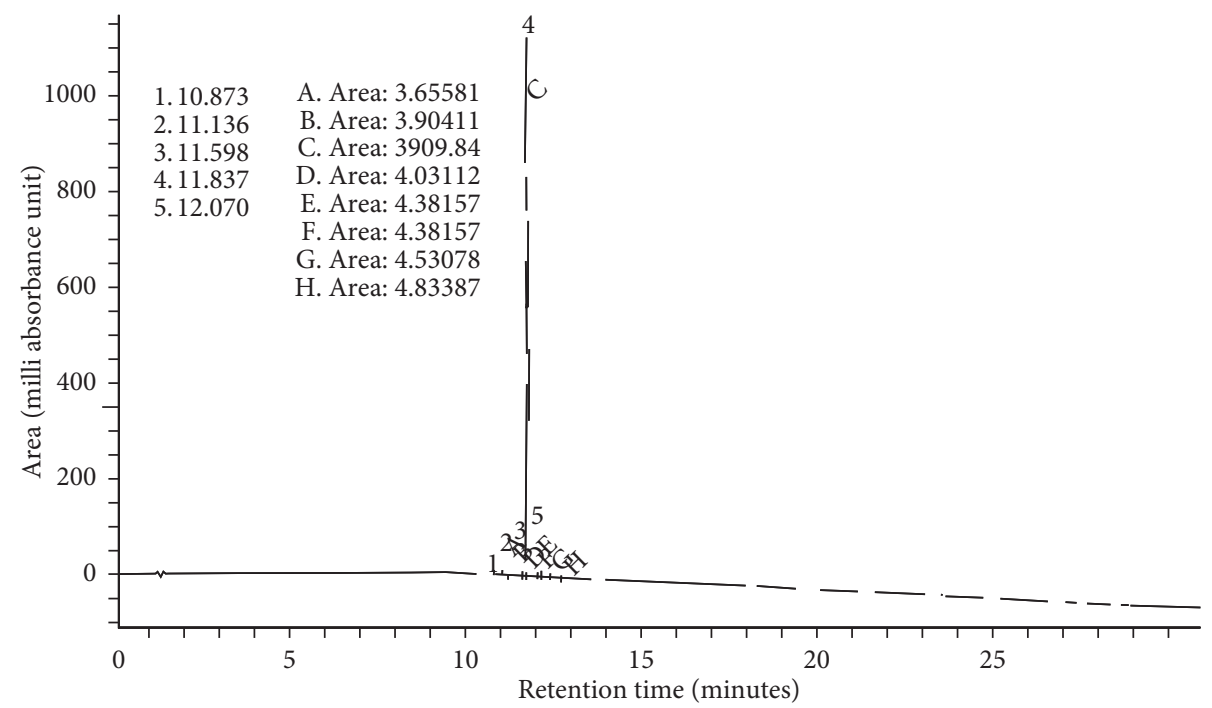

(e)

Figure 4: (a) A chromatograph of isolated anthocyanin molecules of cyanidin-3-O-glucoside $25 \mathrm{mg}$. (b) A chromatograph of isolated anthocyanin molecules of taxifolin $25 \mathrm{mg}$. (c) A chromatograph of isolated anthocyanin molecules of orientin $25 \mathrm{mg}$. (d) A chromatograph of isolated anthocyanin molecules of isovitexin $25 \mathrm{mg}$. (e) A chromatograph of isolated anthocyanin molecules of homoorientin $25 \mathrm{mg}$.

\section{Discussion}

The acai fruit is a multistemmed palm widely distributed in the northern South America. The fruit varies a great deal in the appearance of the plant, flowers, and fruiting products, which can be affected by genetic and environmental components. Other factors can affect the anthocyanin composition of fruits and their pulp, such as the harvest, type of soil, water quality, and spatial localization [11].

The current study aimed to characterize the physicalchemical composition of the anthocyanins present in the acai extract used in this research. The current data will be used to produce a standardized acai dye for use in chromovitrectomy that was first tested in cadaveric eyes [8] and rabbits [9] and now will be used in a phase I/II clinical trial in humans (unpublished data).

Mass spectrometry and HPLC identified and quantified the presence of five anthocyanins in the vital dye of the acai fruit: cyanidin-3-O-glucoside, homoorientin, orientin, isovitexin, and taxifolin. Data showed that cyanidin-3-O-glucoside is the major anthocyanin. These findings agreed with those of previous studies that also found that cyanidin-3-Oglucoside was the major anthocyanin found in the acai extracts $[12,13]$. Results also showed that independent of the concentration of the acai dye, the anthocyanin concentration was similar (Table 3), and this result is probably because we employed the same prime material.

We hypothesized previously [8] that the anthocyanins of the acai fruit might have low potential for causing retinal and RPE toxicity in humans. Spectrophotometry analysis of different dye concentrations from the acai fruit had a peak light absorption around $1,000 \mathrm{~nm}$; it is a fact that the lower the wavelength of the light source, the higher the energy emission and consequently the more toxic the light source is to the retina [7]. The high absorption peak of light from the acai solution suggests that this dye might have a safer toxicity profile regarding light absorption than other currently available dyes. A study that evaluated the absorbance spectra of nine vital dyes for chromovitrectomy found that most had two absorbance peaks, the first below $400 \mathrm{~nm}$ and the other in the visible light ranging from 400 to $700 \mathrm{~nm}$ [6].

In conclusion, the pharmacologic correction of the $\mathrm{pH}$ to 7.00 and osmolarity to $300 \mathrm{mOsm}$ and the lyophilization process were successfully performed. The five major anthocyanins are present in the vital dye extracted from the acai, the major one being cyanidin-3-O-glucoside. Independent of the concentration of the acai dye, the anthocyanin concentration was similar. These standardized chemical characteristics of this new dye may allow its use during chromovitrectomy in humans. Further basic and clinical studies are needed to fully understand the role of acai dye anthocyanins and their antioxidant capacity.

\section{Data Availability}

The data used to support the findings of this study are available from the corresponding author upon request.

\section{Disclosure}

The authors hold a patent related to the intraocular use of anthocyanins from acai fruit (Euterpe oleracea). The patent number (P11333244-8A2) is registered at the National Institute of Intellectual Property, Rio de Janeiro, Brazil. 


\section{Conflicts of Interest}

The authors declare that they have no conflicts of interest.

\section{Acknowledgments}

This work was supported by the Conselho Nacional de Desenvolvimento Científico e Tecnológico, Brasília, Brazil; Fundação de Amparo à Pesquisa do Estado de São Paulo, São Paulo, Brazil; and Pan-American Association of Ophthalmology/Pan-American Ophthalmological Foundation, Paul Kayser Global Award, Arlington, Texas. The authors are grateful to Rubens Belfort Jr., M.D., Ph.D., for donating supplies for the development of this study and to Paulo Schor, M.D., Ph.D., for support regarding application for financial support at Conselho Nacional de Desenvolvimento Científico e Tecnológico, Brasília, Brazil.

\section{References}

[1] H. Rogez, Açaí: Preparo, Composição e Melhoramento da Conservação, Universidade Federal do Pará, Belém, Brazil, 2000.

[2] S. Darnet, J. L. Serra, A. C. Rodrigues et al., "A highperformance liquid chromatography method to measure tocopherols in assai pulp (Euterpe oleracea)," Food Research International, vol. 44, no. 7, pp. 2107-2111, 2011.

[3] D. Del Pozo-Insfran, C. H. Brenes, and S. T. Talcott, "Phytochemical composition and pigment stability of acai (Euterpe oleracea Mart.)," Journal of Agricultural and Food Chemistry, vol. 52, no. 6, pp. 1539-1545, 2004.

[4] M. S. M. Rufino, J. Pérez-Jiménez, S. Arranz et al., "Açaí (Euterpe oleraceae) 'BRS Pará': a tropical fruit source of antioxidant dietary fiber and high antioxidant capacity oil," Food Research International, vol. 44, no. 7, pp. 2100-2106, 2011.

[5] C. S. Peris, E. Badaro, M. A. Ferreira et al., "Color variation assay of the anthocyanins from acai fruit (Euterpe oleracea): a potential new dye for vitreoretinal surgery," Journal of Ocular Pharmacology and Therapeutics, vol. 29, no. 8, pp. 746-753, 2013.

[6] P. Costa Ede, E. B. Rodrigues, M. E. Farah et al., "Vital dyes and light sources for chromovitrectomy: comparative assessment of osmolarity, $\mathrm{pH}$, and spectrophotometry," Investigative Opthalmology and Visual Science, vol. 50, no. 1, pp. 385-391, 2009.

[7] Y. Yanagi, Y. Inoue, W. D. Jang, and K. Kadonosono, "A2e mediated phototoxic effects of endoilluminators," British Journal of Ophthalmology, vol. 90, no. 2, pp. 229-232, 2006.

[8] J. Chen, M. A. Ferreira, M. E. Farah et al., "Posterior hyaloid detachment and internal limiting membrane peeling assisted by anthocyanins from acai fruit (Euterpe oleracea) and 10 other natural vital dyes: experimental study in cadaveric eyes," Retina, vol. 33, no. 11, pp. 89-96, 2013.

[9] R. R. Caiado, C. S. Peris, A. A. S. Lima-Filho et al., "Retinal toxicity of acai fruit (Euterpe oleracea) dye concentrations in rabbits: basic principles of a new dye for chromovitrectomy in humans," Current Eye Research, vol. 42, no. 8, pp. 1185-1193, 2017.

[10] S. Gallori, A. R. Bilia, M. Bergonzi et al., "Polyphenolic constituents of fruit pulp of Euterpe oleracea Mart (Acai palm)," Chromatographia, vol. 59, no. 11-12, pp. 739-743, 2004.
[11] G. C. Cretu and G. E. Morlock, "Analysis of anthocyanins in powdered berry extracts by planar chromatography linked with bioassay and mass spectrometry," Food Chemistry, vol. 146, pp. 104-112, 2014.

[12] A. V. Carvalho, "Chemical composition and antioxidant capacity of acai (Euterpe oleracea) genotypes and commercial pulps," Journal of the Science of Food and Agriculture, vol. 97, no. 5, pp. 1467-1474, 2017.

[13] K. K. Yamaguchi, L. F. Pereira, C. V. Lamarao, E. S. Lima, and V. F. da Veiga-Junior, "Amazon acai: chemistry and biological activities: a review," Food Chemistry, vol. 179, pp. 137-151, 2015. 


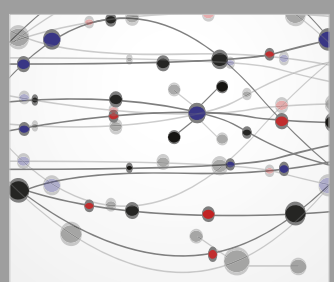

The Scientific World Journal
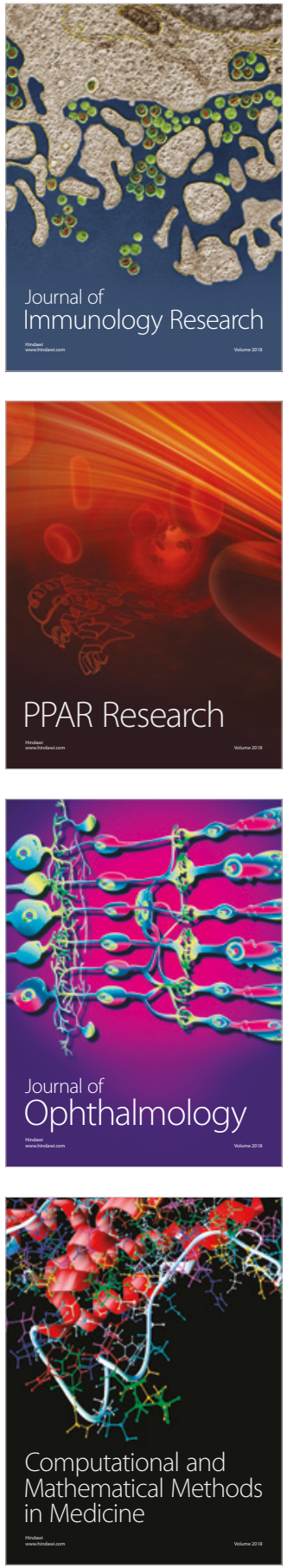

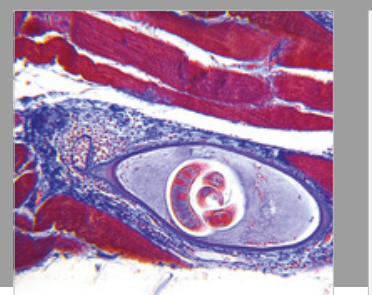

Gastroenterology Research and Practice

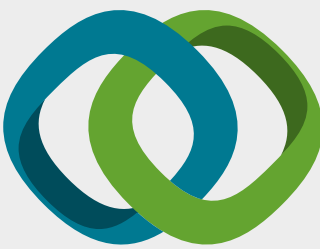

\section{Hindawi}

Submit your manuscripts at

www.hindawi.com
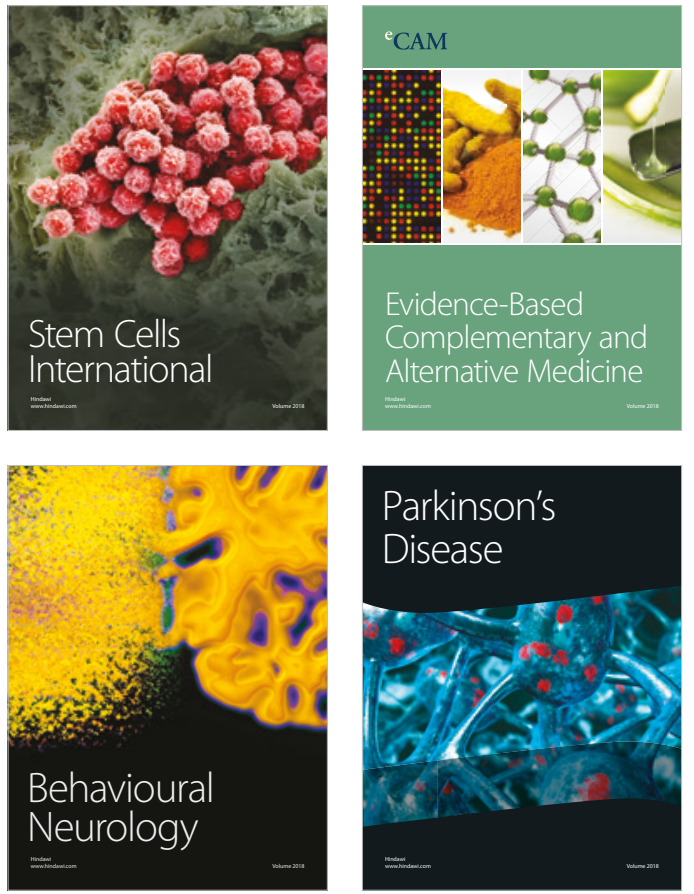

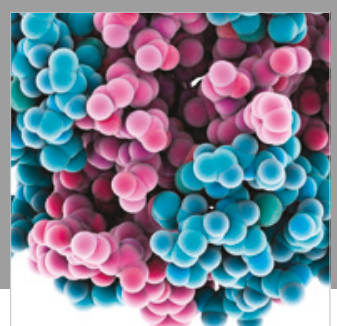

ournal of

Diabetes Research

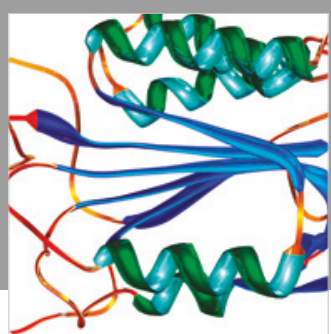

Disease Markers
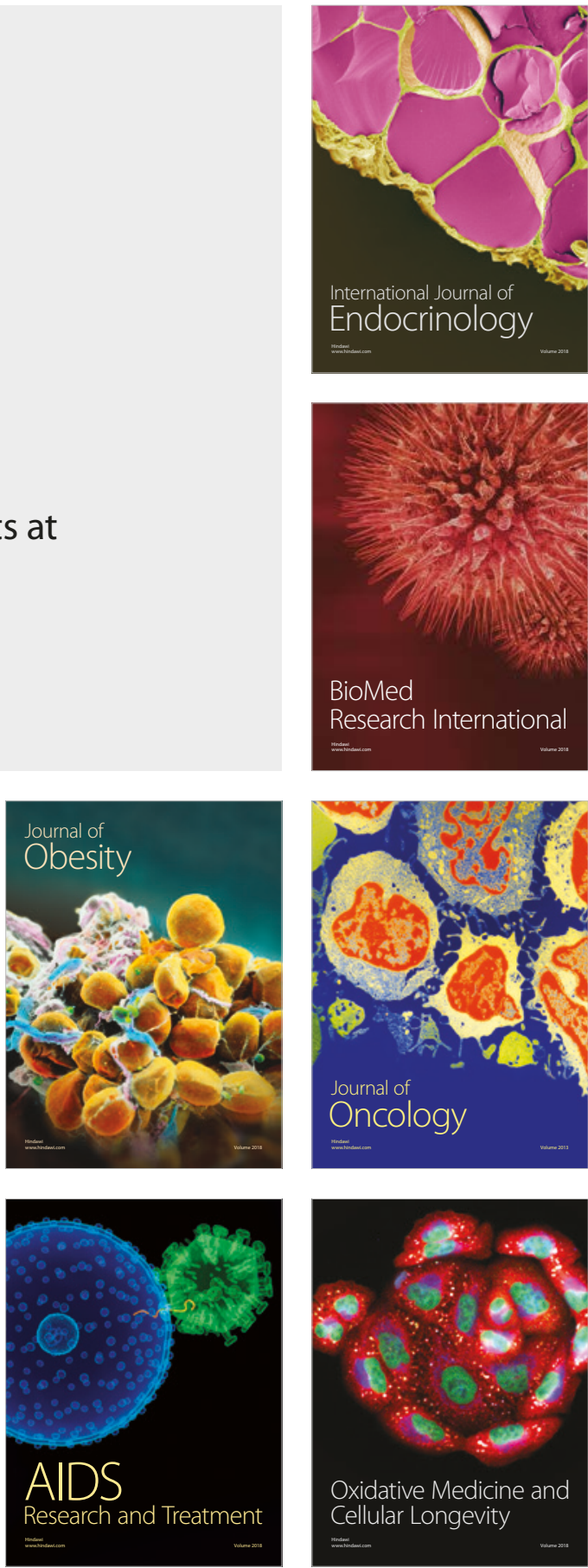